\title{
The J-2X Upper Stage Engine: From Design to Hardware
}

\author{
Thomas Byrd, Deputy Manager, J-2X Upper Stage Engine Element \\ Ares Projects Office \\ Marshall Space Flight Center \\ Huntsville, AL 35812
}

\begin{abstract}
NASA is well on its way toward developing a new generation of launch vehicles to support of national space policy to retire the Space Shuttle fleet, complete the International Space Station, and return to the Moon as the first step in resuming this nation's exploration of deep space. The Constellation Program is developing the launch vehicles, spacecraft, surface systems, and ground systems to support those plans. Two launch vehicles will support those ambitious plans-the Ares I and Ares V. (Figure 1) The J-2X Upper Stage Engine is a critical element of both of these new launchers. This paper will provide an overview of the J-2X design background, progress to date in design, testing, and manufacturing.

The Ares I crew launch vehicle will lift the Orion crew exploration vehicle and up to four astronauts into low Earth orbit (LEO) to rendezvous with the space station or the first leg of mission to the Moon. The Ares V cargo launch vehicle is designed to lift a lunar lander into Earth orbit where it will be docked with the Orion spacecraft, and provide the thrust for the trans-lunar journey. While these vehicles bear some visual resemblance to the 1960s-era Saturn vehicles that carried astronauts to the Moon, the Ares vehicles are designed to carry more crew and more cargo to more places to carry out more ambitious tasks than the vehicles they succeed. The government/industry team designing the Ares rockets is mining a rich history of technology and expertise from the Shuttle, Saturn and other programs and seeking commonality where feasible between the Ares crew and cargo rockets as a way to minimize risk, shorten development times, and live within the budget constraints of its original guidance.
\end{abstract}



Figure 1. The Ares V Cargo Launch Vehicle (left) and Ares I Crew Launch Vehicle (right) will form the backbone of America's new space fleet. (NASA artist's concept) 


\section{The J-2X Mission and Requirements}

The J-2X Upper Stage Engine (USE) exemplifies those goals and made significant progress in 2009 and 2010 in moving from a paper design to hardware for component and major assembly testing. It is based on the proven J-2 engine used on the Saturn IB and Saturn V launch vehicle upper stages. It will power both the Ares I upper stage and the Ares V Earth departure stage (EDS). The prime contractor for the J-2X is Pratt \& Whitney Rocketdyne (PWR), which is under a design, development, test and engineering (DDT\&E) contract that covers the period from June 2006 through September 2014.

For Ares I, the J-2X will provide an engine start at altitude and then second-stage propulsion for a nominal burn period of 500 seconds. For Ares V, the J-2X will provide an engine start at altitude, operation of roughly 500 seconds at either of the two power levels for second stage propulsion, engine shutdown, on-orbit loiter for up to five days, on-orbit restart upon command, engine operation for roughly 300 seconds to execute trans lunar injection, and final engine shutdown. Requirements are summarized in Figure 2 below.

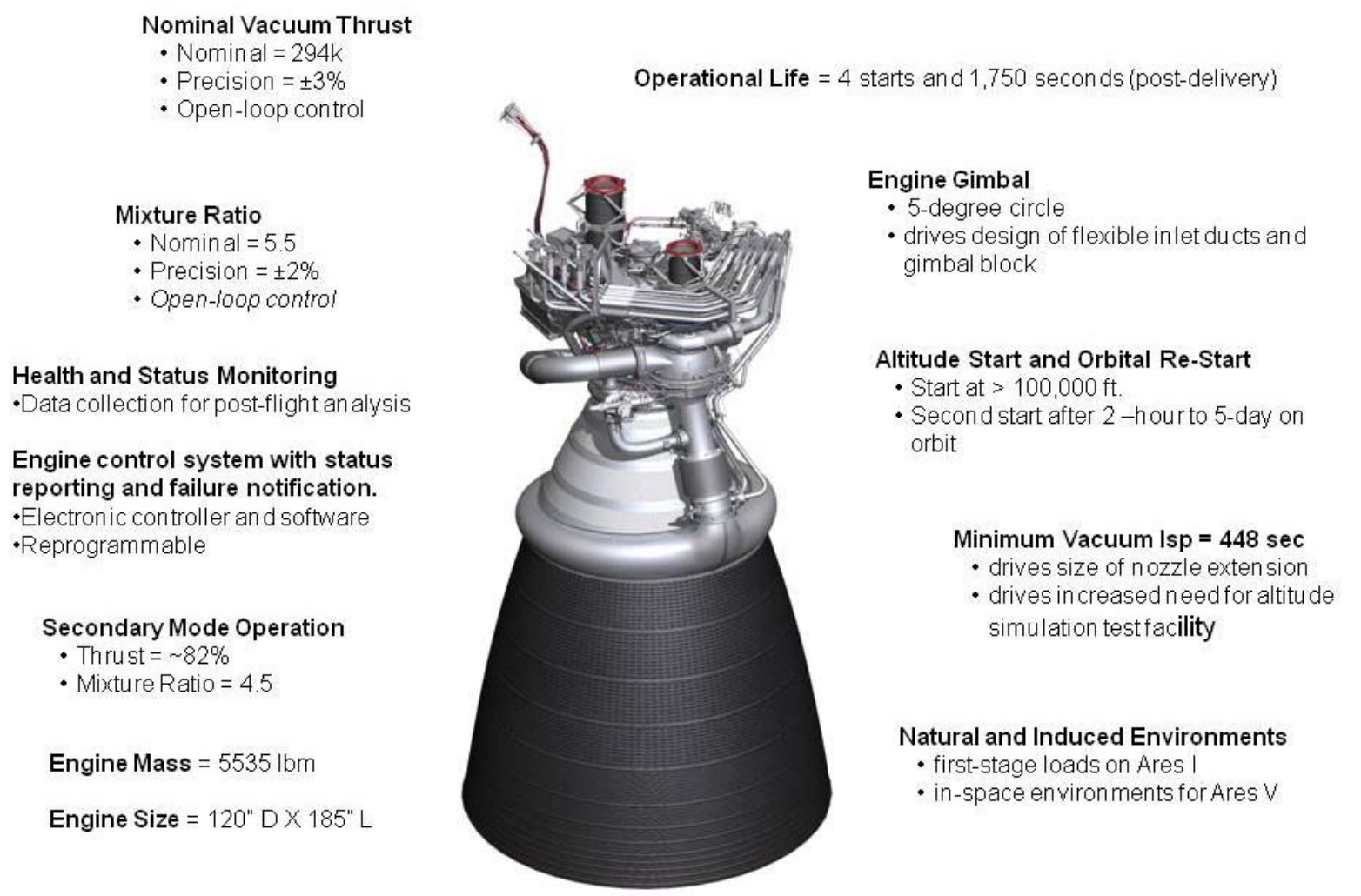

Figure 2. J-2X Key Requirements

The J-2X employs PWR's flight-proven $\mathrm{LH}_{2} / \mathrm{LOX}$, gas generator cycle $\mathrm{J}-2$ and RS-68 engine capabilities, recent experience with the X-33 aerospike XRS-2200 engine, and development knowledge of the J-2S tap-off cycle engine. The Ares I and Ares V vehicles require that the J-2X operate at much higher temperatures, pressures, and flow rates than the Saturn J-2. High efficiency turbines, injectors, and nozzle extension make $\mathrm{J}-2 \mathrm{X}$ performance very high for a gas generator cycle engine, approaching the efficiency of more complex staged combustion cycle engines such as the Space Shuttle Main Engine (SSME). 


\section{J-2X Development and Production}

The J-2X development effort focuses on four key areas, which represent a building block approach to acquire empirical knowledge as the design and analysis of the engine mature:

- Early risk mitigation, including characterization of heritage turbomachinery and valves.

- Design risk mitigation, including characterization of various design features prior to component testing.

- Component and subassembly test.

- Engine system test, including development and certification, as well as support to the Ares I Upper Stage Integrated Stage Test Article (ISTA).

The USE Element successfully completed its critical design review in 2008 with a CDR Board on November 13. At that time, the element scheduled a development baseline checkpoint review to check closure status for open work identified at CDR and establish the development engine design baseline.

Engine hardware now under contract includes nine engine assemblies and one powerpack. The assembled engines will be assigned as follows: five for development ground test, two as certification ground test engines, one Upper Stage Integrated Stage Test Article ground test engine, and one engine for the Orion I test flight. The powerpack assembly is for ground development tests with turbopumps and turbine drive hot gas system.

Post-CDR manufacturing is well under way, including PWR in-house and vendor hardware. In addition, a wide range of component and sub-component tests have been completed, and more component tests are planned. Testing includes heritage powerpack, turbopump inducer water flow, turbine air flow, turbopump seal testing, main injector and gas generator (Figure 4) injector testing, augmented spark igniter testing, nozzle side loads cold flow testing, nozzle extension film cooling flow testing, control system testing with hardware in the loop, and nozzle extension emissivity coating tests.

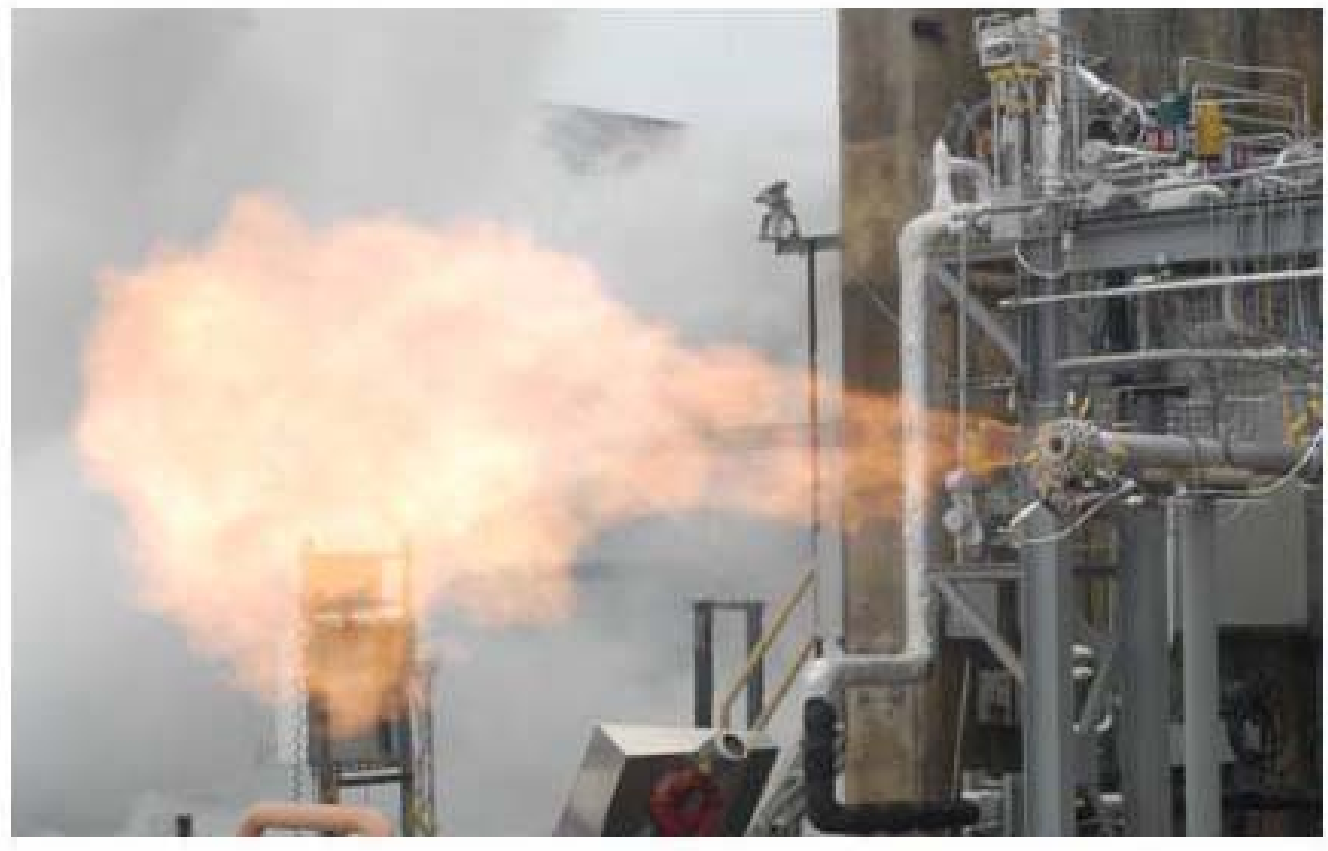

Figure 4. Workhorse Gas Generator Test at MSFC.

In parallel with hardware manufacturing, work is progressing on the new A-3 test stand to support full duration altitude testing. A recent image of A-3 construction is shown in Figure 5. The Stennis A-2 test 


\title{
The J-2X Upper Stage Engine: From Design to Hardware
}

\author{
Thomas Byrd ${ }^{1}$ \\ NASA Marshall Space Flight Center, Huntsville, AL, 35812
}

\begin{abstract}
NASA's J-2X rocket engine is designed to provide upper stage propulsion for the Ares I crew launch vehicle and the Ares $V$ cargo launch vehicle. It is based on the proven Apolloera $\mathrm{J}$-2 upper stage engine. However, it has evolved into a unique propulsion system with considerably more capability than its historic predecessor. Since the $\mathbf{J}-2 \mathrm{X}$ project began in 2006, NASA has made significant progress on the design, testing, supporting facilities, and manufacturing. This paper will summarize engine program and highlight the progress to date.
\end{abstract}

\section{Introduction}

$\mathrm{N}$ ASA is well on its way to developing the most efficient gas generator cycle upper stage rocket engine in history for the next generation of exploration, science, and commerce. NASA selected the J-2X in late 2005 as the common upper stage engine for the Ares I crew launch vehicle and the Ares V cargo launch vehicle. Managed by NASA's Marshall Space Flight Center, the J-2X is part of the Constellation Program. When it was conceived, NASA was seeking to base the program architecture where possible on proven hardware. The Space Shuttle Main Engine (SSME) was originally conceived as the upper stage engine for the Ares I launch vehicle. However, efforts to streamline the Constellation architecture resulted in selection of the J-2X for Ares I, thus making it a common second stage engine for Ares I and Ares V. Analysis showed it would have less development risk and lower development and recurring costs than modifying the SSME. The J-2X design was to be based on the proven J-2 engine developed for the 1960s-era Saturn I and Saturn V launch vehicles. However, it had to meet Constellation's higher thrust, efficiency, and safety requirements for two different vehicles. Since the J-2X was selected, the government/industry development team has made significant progress in the effort to design a new engine that minimizes risk, shortens development times, and lives within budget constraints. Pratt \& Whitney Rocketdyne (PWR), maker of the J-2, is the prime contractor for the J-2X development program. An industry team of nearly 1,700 people nationwide and two foreign countries - including 226 small businesses - have participated in the design and manufacturing of the J-2X. More than 1,500 of 1,600 engine drawings are released for manufacturing. Approximately 100,000 parts are completed or in various stages of manufacturing. The heritage J-2 starting point has aided that rapid progress. In addition, hundreds of hours of advanced computer analysis, heritage J-2 and development component testing have helped the team understand performance issues, evaluate computer models, and inform design trades. This work provides a solid base as the J-2X team prepares for its first engine hot fire testing in calendar 2011. This paper provides a technical update on J-2X development, manufacturing, and testing progress.

\section{Mission, Requirements, Heritage}

For Ares I, the J-2X will provide an engine start at altitude and then second-stage propulsion for a nominal burn period of 500 seconds at a primary thrust level of 294,000 pounds. For Ares V, the J-2X will provide an engine start at altitude, operation of roughly 500 seconds at primary thrust level for second stage propulsion, engine shutdown, on-orbit loiter for up to five days, on-orbit restart upon command, engine operation for roughly 300 seconds at 80 percent of rated thrust to execute trans lunar injection, and final engine shutdown. Engine requirements are summarized in Figure 1 below.

\footnotetext{
${ }^{1}$ Deputy Manager, Upper Stage Engine Element, Ares Project
} 


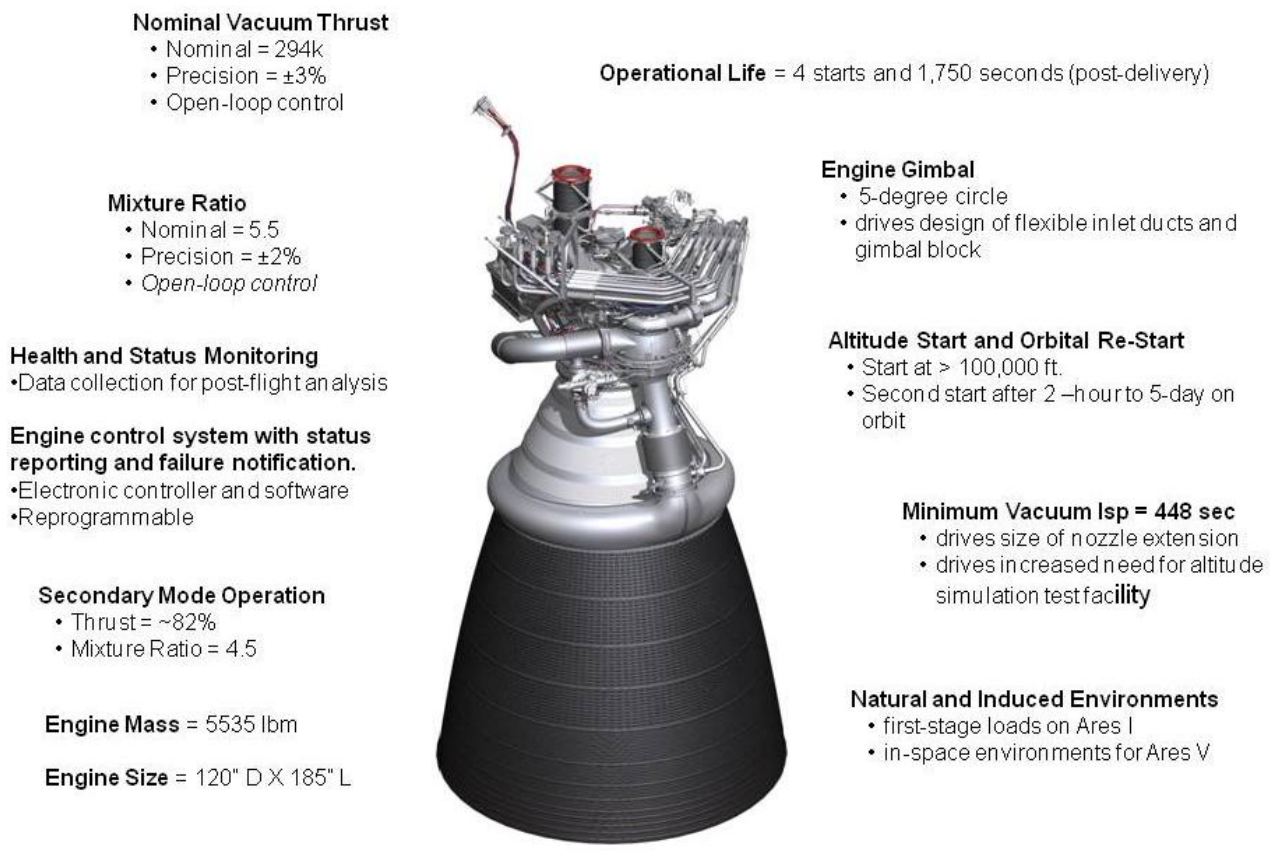

Figure 1. J-2X requirements overview

The Ares I and Ares V vehicles require that the J-2X operate at much higher temperatures, pressures, and flow rates than the Saturn J-2. For instance, the requirement for greater mass delivered to the Moon is largely responsible for higher J-2X thrust and specific impulse requirements. The $\mathrm{J}-2 \mathrm{X}$ must also meet greater loss of mission reliability and numerous other requirements associated with human rating that were not applied to the original $\mathrm{J}-2$.

In order to mitigate the risk normally associated with a new engine development, the $\mathrm{J}-2 \mathrm{X}$ draws upon both technology and knowledge base from PWR's flight-proven LH2/LOX, gas generator cycle J-2 and RS-68 engines, the X-33 aerospike XRS-2200 engine, and the J-2S tap-off cycle engine. From this rich knowledge and experience base, the J-2X has evolved into essentially a new engine based on the more stringent Ares requirements.

High efficiency turbines, injectors, and nozzle extension enable the J-2X to perform with an efficiency approaching that of a more complex staged combustion cycle engines such as the Space Shuttle Main Engine (SSME). The J-2S Mk 29 turbopump provides a point-of-departure for the J-2X turbomachinery. The design team deviated from that design only as needed to meet performance requirements, design criteria, and convert to modern materials. PWR's RS-68 engine, operational on the Delta IV, also served as the basis for several other major J-2X components. To achieve 448 seconds of specific impulse, the gas generator engine cycle required a high area ratio exhaust nozzle. The J-2X employs a regeneratively-cooled nozzle and a nozzle extension passively cooled by an emissivity coating on its inner and outer surfaces and by turbine exhaust gas injected around the inner wall.

\section{Current Development Hardware and Test Plans}

Since completing critical design review (CDR) in 2008, the element has finalized its development test plan and hardware inventory as described in this section. Engine development hardware finalized at CDR includes:

- 9 development engines, including the first flight engine and an engine for upper stage ground testing

- 2 powerpack assemblies

- 4 long-lead hardware sets

- 1 unassembled spare engine

- 1 engine mass simulator

- 7 full nozzle extensions and two "stub" length extensions

- 1 set of spare fuel and oxidizer turbopumps

- 1 set of hardware/software for the Hardware in the Loop Lab (HILL)

- 1 control system for the Ares System Integration Lab

- various engine support hardware, manufacturing technology demonstrators, and component test articles.

2

American Institute of Aeronautics and Astronautics 
The J-2X development plan provides for a total of 223 engine tests as follows:

- 132 development tests

- 32 certification tests

- 7 development/flight tests for the engine to be flown on the first Ares I test flight

- 15 tests of the engine with the Ares I Upper Stage Integrated Stage Test Article

- 17 contingency tests

- 20 rework tests

In comparison to the Saturn development program, PWR records indicate that the heritage J-2 underwent approximately 3,000 single engine firing tests, 419 cluster tests, and 110 dull-duration tests, accumulating more than 470,000 seconds of hot fire time. The J-2X development team believes it has created a prudent program based on proven hardware, team experience, and the wise use of both analysis and early testing.

\section{Development Testing Highlights}

The $\mathrm{J}-2 \mathrm{X}$ development approach is built around early risk mitigation testing, design risk mitigation, component and subassembly test, and engine system testing.

Risk mitigation testing of heritage components began soon after the element's creation and has played a major role in gaining a baseline understanding of the J-2 using today's computer simulation, instrumentation, and test techniques. That testing has included oxidizer and fuel inlet duct durability, gas generator stability, nozzle extension performance/durability, oxidizer and fuel turbopump structural margins, and main injector and igniter performance,

Subscale main injector hot fire tests ran from 2006 to 2007. They helped establish the J-2X injector element pattern with the best performance with minimum complexity and cost. The test hardware simulated the element density chosen for the full-scale injector. Subscale injectors with densities of 40, 52, and 58 elements were subjected to conditions simulating the J-2X operating environment. The 52-element injector, which is simpler overall than the SSME main injector, was selected for development. A hot fire test is shown in Figure 2.

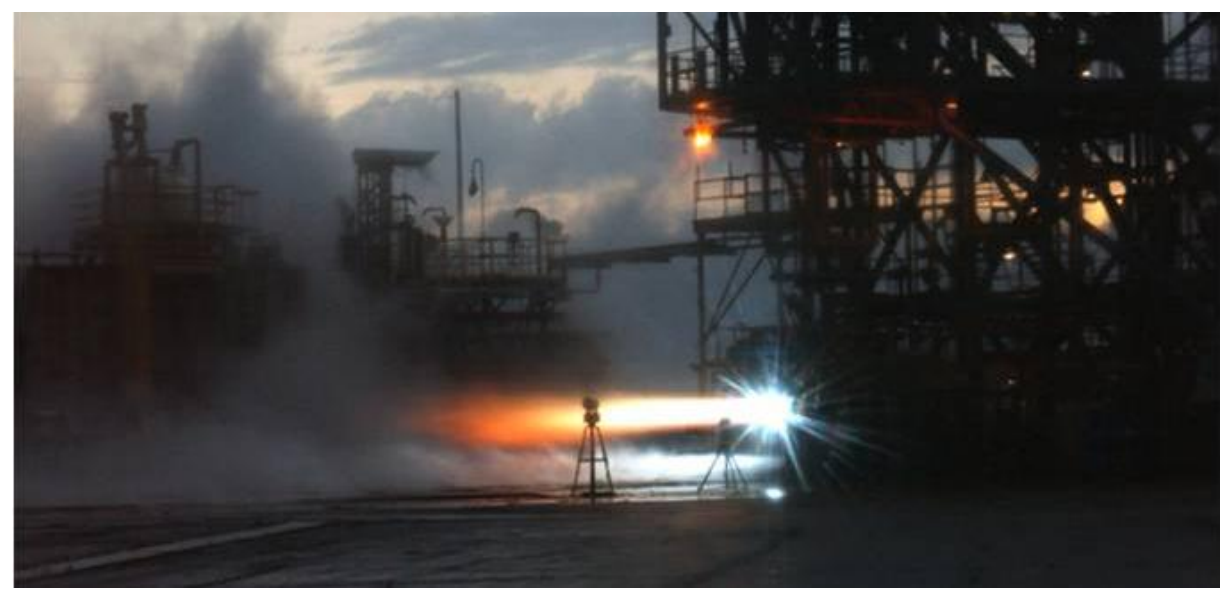

Figure 2. J-2X subscale main injector test

J-2 main injector augmented spark igniter (ASI) testing in 2007 simulated both altitude start conditions during the ascent phase and the low temperatures the ASI would experience during a trans lunar injection (TLI) burn on missions beyond LEO.

NASA's workhorse gas generator (WHGG) test facility supported several hot-fire test series in 2008 and 2009. It simulated the temperatures, pressures, and flows of a flight gas generator. It was used to study performance, combustion stability, and turbine inlet hot gas temperature. Tests began with a simple straight hot gas discharge duct before incorporating a more flight-like elbow and U-duct connecting the GG to the fuel turbine inlet. Both 61-and 
43-element injectors were tested with straight and 90-degree chamber designs. Tests also simulated the 294,000pound primary thrust and 240,000-pound secondary thrust levels specified for the engine.

The WHGG was also used to select a GG chamber length and injector element pattern. A new 43-element injector that increases the GG primary thrust stability margin was successfully tested in 2009. The test apparatus was used again in 2009 to resolve combustion stability issues with the original hot gas discharge duct connecting the GG to the fuel turbine. Five shorter duct lengths were tested using the redesigned injector discussed above. The most promising candidate was selected for use in Power Pack Assembly 2 (PPA-2) and the first development engine, designated E10001. A final series to verify the GG injector with the shortened discharge duct is planned for 2010. A WHGG test is shown in Figure 3.



Figure 3. Workhorse gas generator test at MSFC

As noted above, the $\mathrm{J}-2 \mathrm{Mk} 29$ turbopumps serve as the starting point for the $\mathrm{J}-2 \mathrm{X}$ tubomachinery in order to minimize development risk. J-2X relies on high technology readiness level (TRL) technology with flight experience, together with high-order analyses. The J-2X design challenge has perhaps been most acute for turbomachinery for four reasons: the constrained Mk. 29 pump design baseline; the higher thrust and Isp requirements creating greater internal stresses; contemporary design standards, such as considering alternating stresses, resulting from lessons learned in the years since the J-2 was developed; and new, more refined computer analysis techniques, not yet verified through testing.

The Powerpack Assembly-1 (PPA-1) test series from December 2007 through May 2008 went beyond component-level testing to re-establish the baseline performance of heritage J-2 turbopumps, helium spin start, gas generator, heat exchanger, spark igniter and inlet ducts as input to the new J-2X environments. A total of six "hotfire" tests were conducted. The government/industry engine team amassed more than 1,343 seconds of powerpack operating time at power levels up to an equivalent 274,000 pounds $(1,219 \mathrm{kN})$ of thrust.

This series helped resolve differences in heritage turbopump performance data and recent component-level tests. It investigated the performance of the engine inlet scissor ducts. The oxidizer turbopump (OTP) was subjected to an additional suction performance test during the last powerpack test to explore the effects of helium ingestion on the suction performance. The second power pack series, designated PPA-2, will subject the new J-2X turbomachinery, gas generator, etc. to a series of 25 tests. This series is planned for early 2011. PPA-1 testing is shown in Figure 4. 

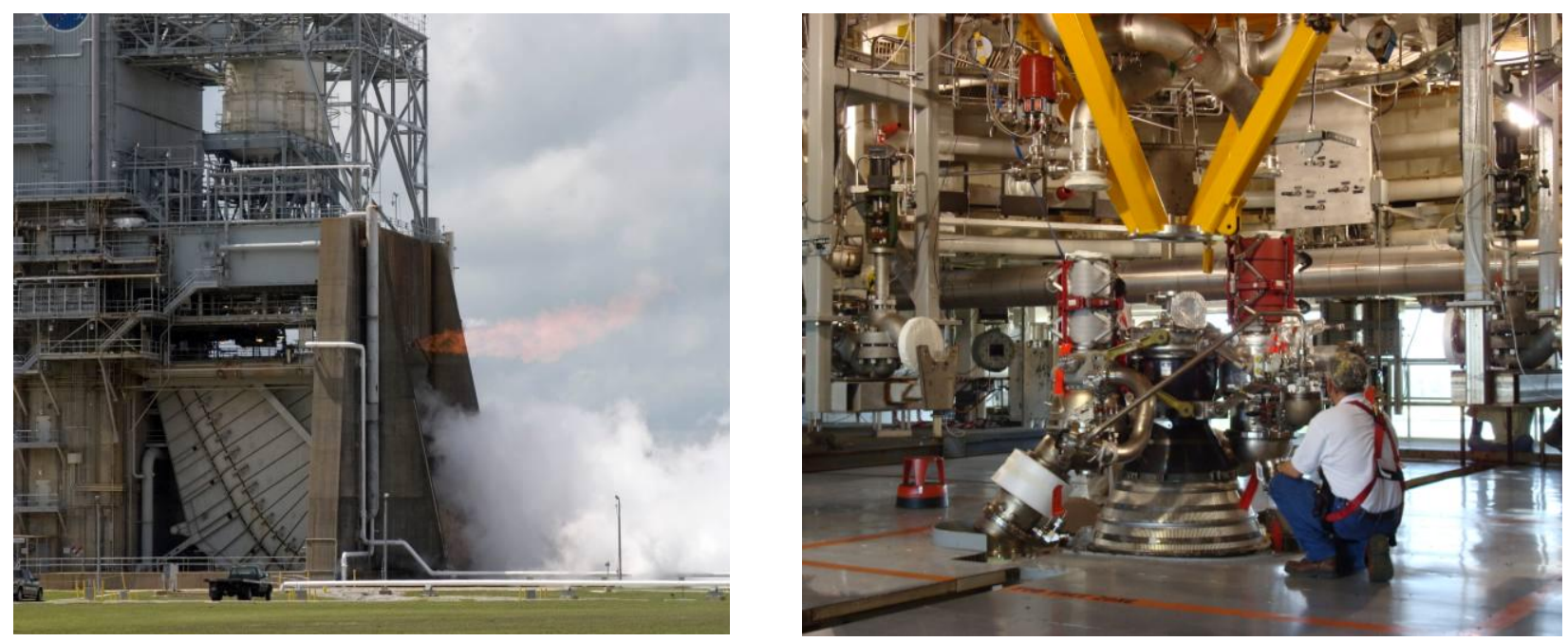

Figure 4. Power Pack 1 test, left, and hardware closeup, right, at SSC

The design of the fuel turbopump (FTP) has been perhaps the most challenging to design because it experiences a significant increase in operating environment to meet the engine's increased thrust and Isp requirements. The LOX pump faces a less harsh environment, but the higher LOX fluid density places particular stress on the inducer and impeller. Design work in response to these increased operating requirements has been extensive. For example, CFD analysis indicated low rotordynamic stability margins in the fuel turbopump, which drove the decision to employ hydrostatic bearings, successfully tested on the Integrated Powerhead Demonstration (IPD) engine developed jointly by the Air Force and NASA. It was test fired nearly 30 times in 2005-2006 but never employed in a flight engine until J-2X.

PWR performed subscale fuel inducer water flow tests, while NASA/MSFC performed subscale LOX inducer water flow tests to assess inducer steady and unsteady performance. The heritage shrouded three-bladed inducer was tested, along with alternate configurations. As a result of testing, the LOX pump inducer design was modified to a more contemporary two-bladed un-shrouded design.

PWR also conducted "whirligig" tests of heritage J-2S fuel turbine first stage using a modified disk and heritage turbine blades to verify the fundamental modes for predicted high cycle fatigue (HCF), as well as the design for blade dampers to attenuate higher-order modes. Blade dampers are being optimized for each turbine stage. Installation of the dampers for each stage may occur as early as the PPA-2 test series.

Interpropellant (IP) seal testing on the LOX pump was performed at MSFC to verify the new helium buffer design and materials before selecting a new seal package to replace the obsolete J-2S design and materials. Some of the turbomachinery tests noted above are shown in Figure 5. 



Figure 5. Turbomachinery testing, clockwise from upper left: PWR waterflow test, MSFC waterflow test, PPA-1 OTP, PWR whirligig test.

The J-2 Heritage Fuel Airflow Turbine Test (HFATT) series in 2010 was the most heavily instrumented turbine air flow test rig NASA has ever employed. It was used to characterize turbine performance and load environments for anchoring turbine gas CFD modeling. This new tool is particularly important for the development's constrained hardware and test budget. The test rig simulated full scale J-2 fuel turbopump primary flow path, including inlet manifold and disk cavities, with emphasis on sensor installation on the first and second stage blades and rotor disks. HFATT provided steady and unsteady pressure mapping of the turbine blade environments and measured the contribution of interstage cavity pressures to turbine axial thrust. Operating conditions tested included spin start, engine start, 274,000 lb and 294,000 lb thrust levels, and engine shutdown. A total of 90 rotating dynamic measurements and 38 stationary dynamic measurements were collected via instruments on the two rotor stages, the backing cavity above the turbine blades, and the disk cavities. Various test features are shown in Figure 6. 



Figure 6. HFATT test hardware clockwise from upper left: 1 st rotor blades (40 sensors), 2nd rotor blades (30 sensors), Intermediate Stator ( 23 sensors), Turbine Manifold (8 sensors)

The J-2X metallic nozzle extension is critical to gaining the performance needed for the Constellation missions. At 10 feet in diameter at the exit plane and nearly 8 feet in length, this extension will be among the largest passivelycooled nozzle extensions. It must survive vibration and thermal stresses the engine, the vehicle, and the flight regime, most notably peak operating temperatures near 2,000 degrees F. Also challenging the design is nozzle side loading caused by asymmetric pressure distribution in the nozzle, particularly during engine start and shutdown. The use of hydrogen-rich turbine exhaust gas (TEG) film cooling and thermal emissivity coatings are also significant factors in ensuring that the operating environment doesn't exceed performance limits.

Subscale cold flow nozzle testing with an instrumented nozzle in 2006 and 2007 in MSFC's wind tunnel facility was used to characterize side loads. The testing optimized the J-2X nozzle to achieve minimum loading while maintaining maximum performance. These tests also helped determine design margins that affected weight and life, as well as performance.

Additional tests in 2009 were used to predict TEG film cooling performance for the nozzle extension. While the heritage J-2 used turbine exhaust dumped into the nozzle to provide some marginal cooling and efficiency, turbine exhaust in the $\mathrm{J}-2 \mathrm{X}$ will be injected supersonically via a manifold to provide a cooler wall temperature and Isp gain. In testing, air chilled to approximately 32 degrees $\mathrm{F}$ ( 0 degrees $\mathrm{C}$ ) was used as the coolant with static pressure measurements along the extension. The tests anchored CFD analysis for the TEG flow. Uncertainty regarding TEG flow performance and nozzle extension cooling effectiveness will be resolved during engine testing. The subscale cold flow nozzle test rig is shown in Figure 7. 

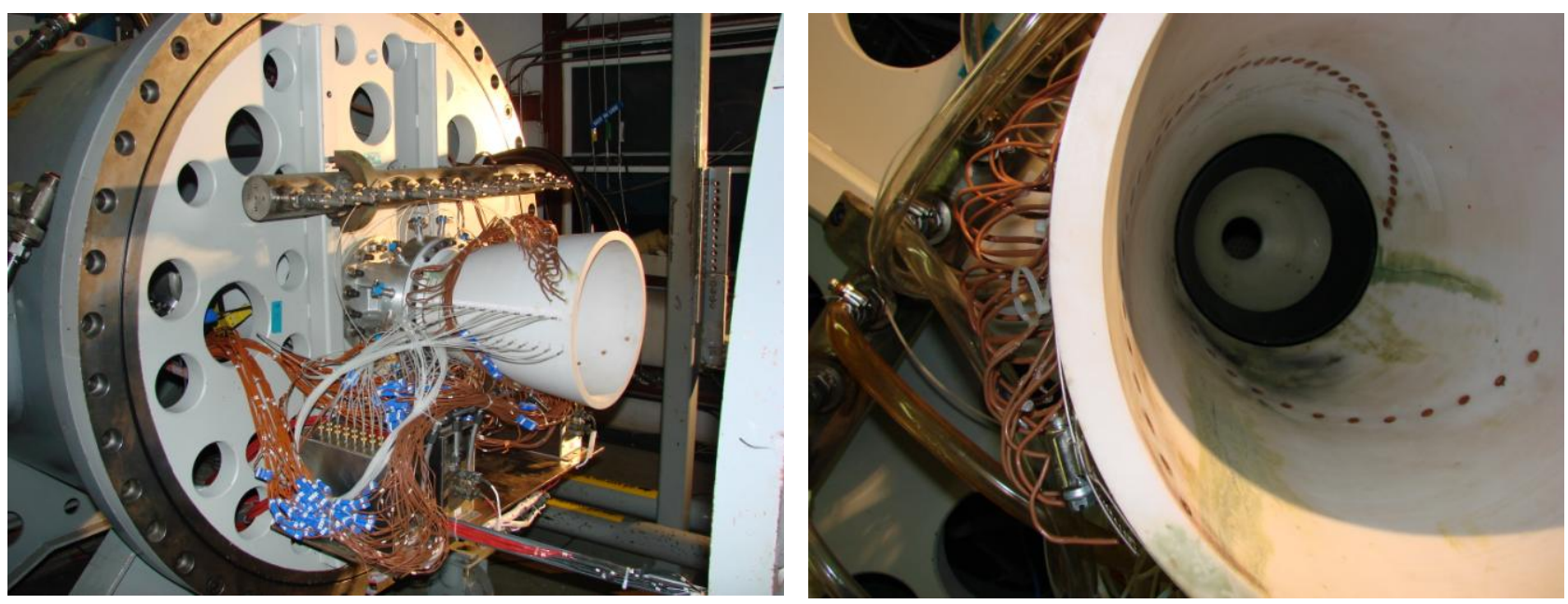

Figure 7. Subscale cold flow nozzle test setup, left, and nozzle interior showing sensors, right

The metallic nozzle extension's inner and outer surfaces will be coated with a commercially-available thermal emissivity coating. It must be capable of surviving 500 seconds of operating time on Ares I and 1,000 seconds of operating time on the Ares V. Seven candidate materials were selected for testing in 2009 and 2010 in MSFC's hot gas facility to characterize their thermal performance and durability. The candidates were reduced to two for further tests in 2010, with one coating selected as the baseline design for the nozzle extension. The nozzle extension service life is 1,600 seconds and 6 starts. The required certification time is twice the rated service live, or 3,200 seconds and 12 starts. The candidate coatings were tested to show they could meet the service life, and the down-selected coatings were tested to the required certification time.

The coatings were sprayed on several small samples of Haynes 230 aluminum machined to the same thickness and orthogrid geometry of the full nozzle extension. During the series, different batches of coatings were applied to the panels to determine if coating performance were subject to random variables in manufacturing. Engineers also tested the ability to repair coating defects that might occur during extension fabrication or during engine testing. Thermocouples, heat flux gauges and other high temperature instrumentation was tested as part of the emissivity series. Panel test samples are shown in Figure 8.
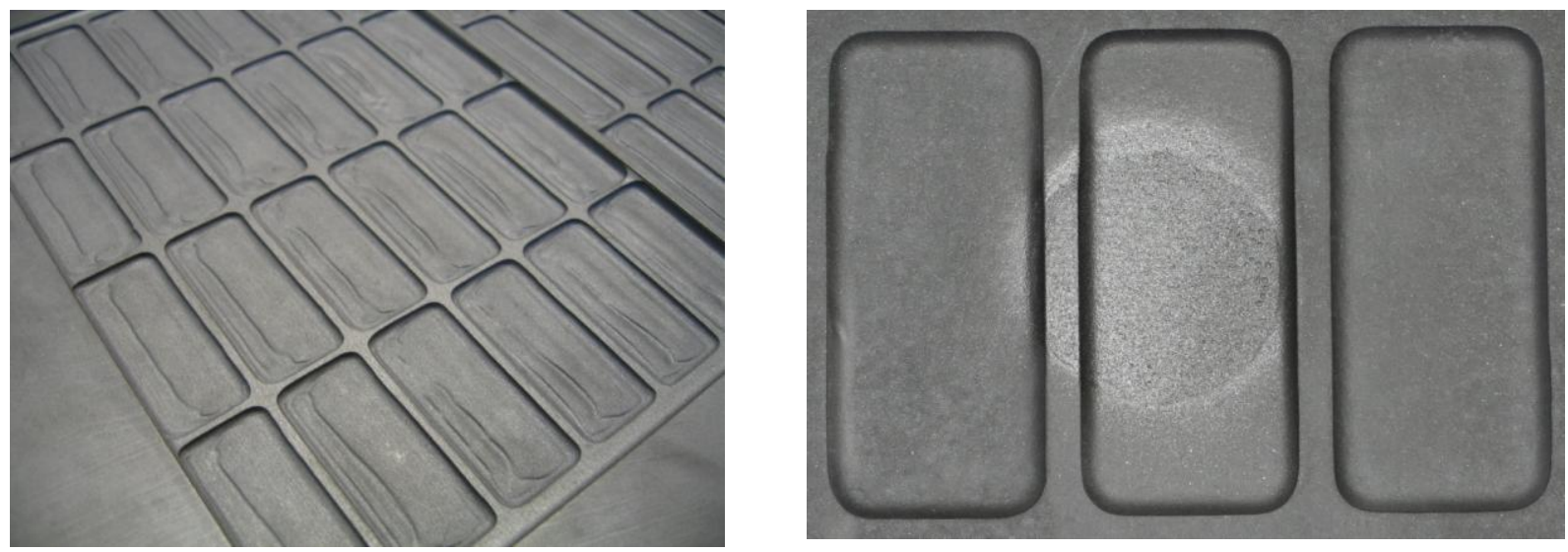

Figure 8. Thermal barrier coating panel showing 'ridging,' left, and test repair, right 
Tests of the upper stage ullage settling motors for Ares I provided an additional opportunity to subject the nozzle extension coatings to possible motor plume impingement. The ullage motors use solid propellant, and the exhaust plume contains relatively large, high-speed particles, essentially sand-blasting any surface that it encounters. Posttest inspection showed that the coatings survived the exposure, with no indications of erosion and no changes in preand post-test emissivity.

The engine's controls, valves, and instrumentation (CVI) hardware has also been the subject of extensive testing. The J-2X employs 43 valves and actuators. Also critical are engine avionics, including the Engine Control Unit, Pneumatic Control Assembly, Main Igniter Exciter Unit, Engine Data Acquisition Unit, and software.

In all cases, the challenge facing the CVI team was designing to accommodate the higher pressures and temperatures associated with the $\mathrm{J}-2 \mathrm{X}$ and the larger physical dimensions of the hardware. Risk mitigation testing in the form of flow tests and cycle tests informed main valve design. Development testing started in fiscal 2010 on main valves and ancillary valves. Much of the design and testing in CVI was related to two new valves the Oxidizer Turbine Bypass Valve (OTBV) and the Helium Spin Start (HSS) valve. Neither of these valves was present in the $\mathrm{X}-33$ engine hardware on which the $\mathrm{J}-2 \mathrm{X}$ hardware is based.

Unlike the fuel or oxidizer valves, the OTBV is subject to temperatures ranging from minus 400 degrees (LOX) to 750 degrees for hot exhaust gas in the span of one second. Altering the engine mixture ratio, via the OTBV is the primary means of generating the engine's secondary thrust level driven by the Ares V TLI engine requirement. The OTBV is hit by temperatures changing rapidly from cryogenic to hot gas and back to cryogenic during a fuel rich shut down. It uses a new seal material, Vespel 211 by Dupont, that works well at cryogenic temperatures. The OTBV seal material testing was done mainly by PWR with molecular testing at MSFC.

The key to ensuring the operation of these devices is the new Hardware in the Loop Lab (HILL) at MSFC. It will support software validation and verification test work and provide a test bed for initial integration of J-2X control and monitoring hardware and software, system level testing, and control system anomaly resolution. The HILL will deploy four software test methods for ECU software testing: analog fault insertion, digital fault insertion, software trace ability, and software test patch.

A J-2X control system simulator will be used for the Upper Stage's Systems Integration Lab/System Integration Test Facility.

Design of the 1,400 square foot HILL facility was completed in July 2008 and construction was completed in 2009. Activation began in 2009 and is continuing in 2010. Full operating capability is planned for July 2011. Prototype hardware has been delivered for testing. Software coding is nearly complete. Software/hardware integration testing and instrumentation development testing is under way. Engine control system verification planning is also ongoing.

The government/industry engine team has made the most efficient use of expertise and facilities. A prominent example of that is the use of government task agreements (GTA) between NASA and PWR. That testing, including some mentioned above has included:

- Material Testing

- Oxygen Compatibility Assessment

- High Speed Data Acquisition \& Process

- Inlet Duct Heater Test

- Control System Testing

- Simulation Interface Adapter

- Pressure Test on Vented Microswitch

- Heritage Valve Testing

- Disassembly Tooling

- Air Flow Testing

- Seal Testing

- Water Flow Testing

- 40K Injector Subscale Test 
- Subscale Injector Test

- Main Injector Augmented Spark Igniter Test

- GG Workhorse Design Test

- Subscale Cold Flow Nozzle Side Loads Test

- Subscale Cold Flow Nozzle TEG Flow Test

- Thermal Emissivity Coating Test

\section{Manufacturing Highlights}

The current focus of manufacturing activity at PWR and its vendors is completion of Engine 10001 (E10001) and PPA-2 to support hot fire test operations in early 201 at Stennis Space Center. The J-2X development engine program currently employs nearly 500 PWR engineers and technicians and more than 1,200 suppliers across the United States, as well as two other countries. To date, approximately 1,500 of 1,600 engine drawings have been released. Nearly 3,500 pieces of hardware for the first seven development engines are completed or in various stages of completion, and more than 1,500 pieces of hardware are completed or in process on PPA-2.

All E10001 complex combustion device hardware are either near assembly or in assembly. The regeneratively cooled nozzle was nearly completed the initial assembly and was entering brazing operations as this paper was in preparation in late June. The main injector was near assembly with all detailed parts needed for initial assembly operations received and most of the details for final assembly received as well. For the first assembly operation the injector posts, the LOX dome, the interpropellant plate (IPP), and the necessary tooling were all completed except for IPP plating.

The main combustion chamber (MCC) was entering Hot Isostatic Press (HIP) assembly. The jacket consists of three machined forgings electron beam (EB) welded together, further machined, then plated. The throat supports have been machined and plated. The throat support pins are completed and plated. The liner has been fully slotted and plated. All components are prepared for HIP assembly.

The Gas Generator (GG) is nearing assembly. The GG injector body for both E10001 and PPA-2 has progressed from casting to machining, and were ready for plating. The injector body combined with other already completed detailed parts such as the injector posts, faceplate, and LOX dome create the GG final assembly.

The E10001 fuel turbo pump (FTP) balance assembly was near completion, to be followed by final assembly. The E10001 oxidizer turbopump (OTP) was in entering balance assembly operations. The majority of all turbomachinery parts for both E10001 and PPA-2 were complete.

Housings for all of the main valves were being machined. The main fuel valve (MFV) housing, main oxidizer valve (MOV) housing, \& oxidizer turbine bypass valve (OTBV) housing were in process at PWR with other detailed components simultaneously being produced by outside suppliers. Work was also under way on other valves such as the gas generator oxidizer valve (GGOV) and the gas generator fuel valve (GGFV).

Propellant duct fabrication was well under way with ducts such as the MCC coolant duct and the oxidizer turbine bypass duct both bent to final contour, flanges final machined, weld jigs built, and in weld operations. All cold rigid duct (CRD) flanges had completed final machining. Other complex duct components had also made significant strides, including the heat exchanger coil whose unique manufacturing process has been fully developed, with completion of the first five units supporting the first four engines and PPA-2.

The process of bending the numerous ancillary lines and preparation for welding on their respective flanges was underway. The tube stock had been received and several part numbers had already progressed through bending and clean and were awaiting weld assembly of their respective flanges.

Assembly of the E10001 regenerative nozzle assembly was under way. The forward base ring fully alloyed for braze. All three flatbands around the braze tubes were ready for plating. The turbine exhaust manifold base ring was in machining, and the regenerative nozzle tubes were fully alloyed for braze. The main injector was rapidly approaching braze assembly with the interpropellant plate received. The LOX dome was nearing completion. LOX 
post assemblies were in stick, and the augmented spark igniter (ASI) was ready for braze. Examples of major components manufactured to date are shown in Figure 9.
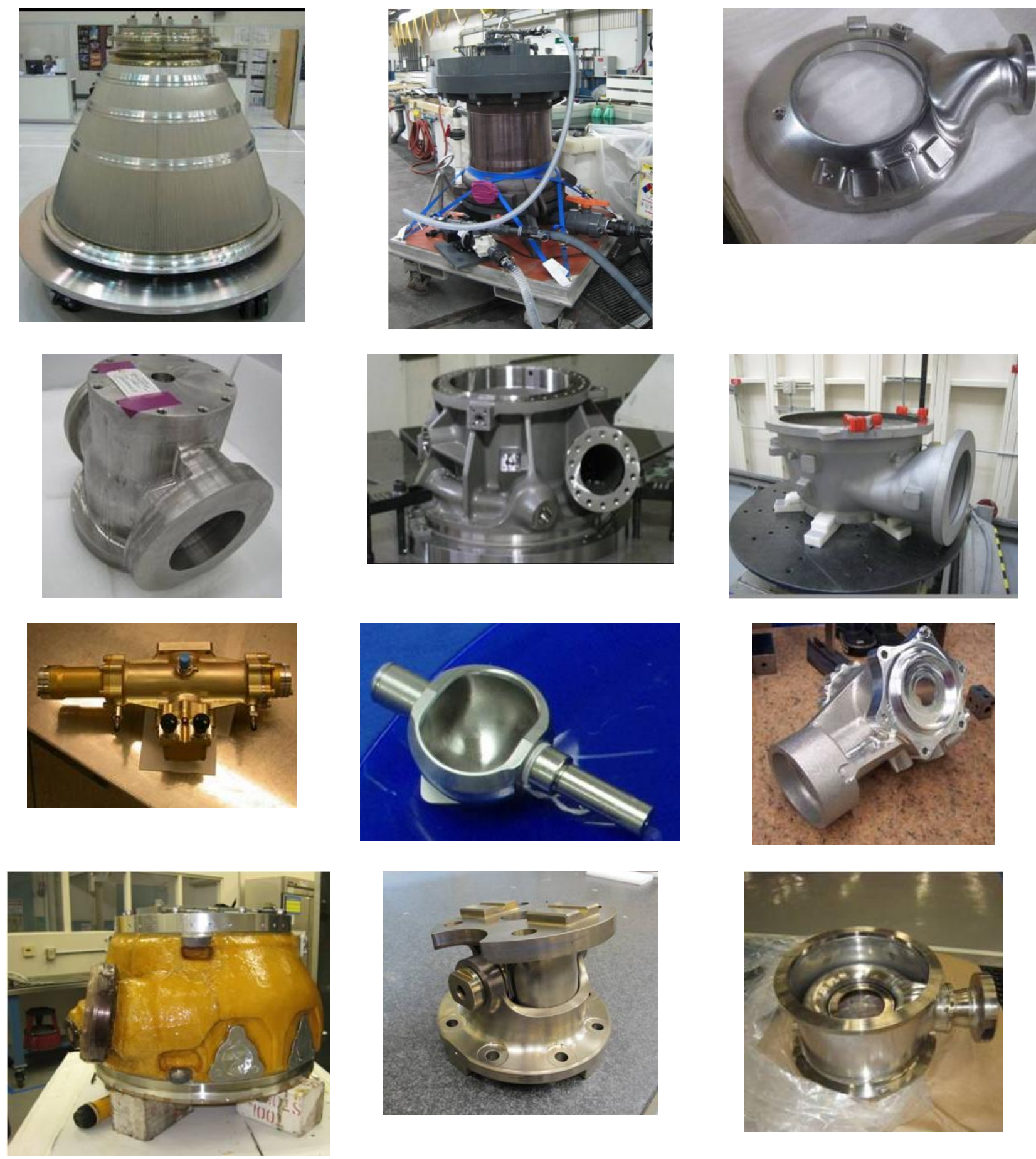

Figure 9. L-R, top to bottom: E10001 nozzle tube stack and flat bands, E10001 MCC, E10001 LOX dome, E10001 MOV housing, PPA-2 FTP volute, PPA-2 OTP turbine manifold, E10001 GGFV actuator, E10001 GGFV ball shaft, E10001 GGOV actuator, FTP volute, gimbal bearing assembly, OTP turbine manifold 


\section{Test Facilities}

Work is under way to have the necessary test facilities ready for engine testing beginning in 2011. Three test stands at Stennis Space Center (SSC) will support J-2X engine testing.

The A1 stand was used for PPA-1 testing in 2008. It is undergoing modifications to support PPA-2 testing beginning in February 2011. Lessons learned in PPA-1 testing are being incorporated, such as the impact of flowinduced loads on facility piping that required additional support. A new thrust frame, a new thrust measurement system and an improved control system have been installed. Facility pump discharge piping and feed line designs were altered to accommodate the different test article configurations for PPA-2 and J-2X engines.

The A2 stand, which supported the Apollo Program and the SSME Program, was turned over to the J-2X team in April 2010 to begin refurbishing to support accelerated development of the J-2X, also with a February 2011 facility ready date. A2 will provide a pseudo-altitude capability using the same passive diffuser used for SSME testing. A2 will perform development and certification engine testing for $\mathrm{J}-2 \mathrm{X}$ engines. Engine configuration is limited to the regenerative nozzle without nozzle extension or the regenerative nozzle and a lower-area-ratio "stub" nozzle extension, and no gimbal capability. In preparation for testing, propellant transfer lines to the run tanks will be replaced in 2010.

2010 plans for A1 include work on the LOX upper and lower run lines, helium spin start system, gaseous oxygen and hydrogen, liquid hydrogen pump capture and LOX pump capture systems. Work on A2 call for procurement and installation of the facility control system, thrust frame assembly, LOX and liquid hydrogen feed ducts, turbine flow meter, piping fabrication, and fabrication and installation of the thrust measurement system electrical and mechanical system. Test stands A1 and A2 are shown in Figure 10.

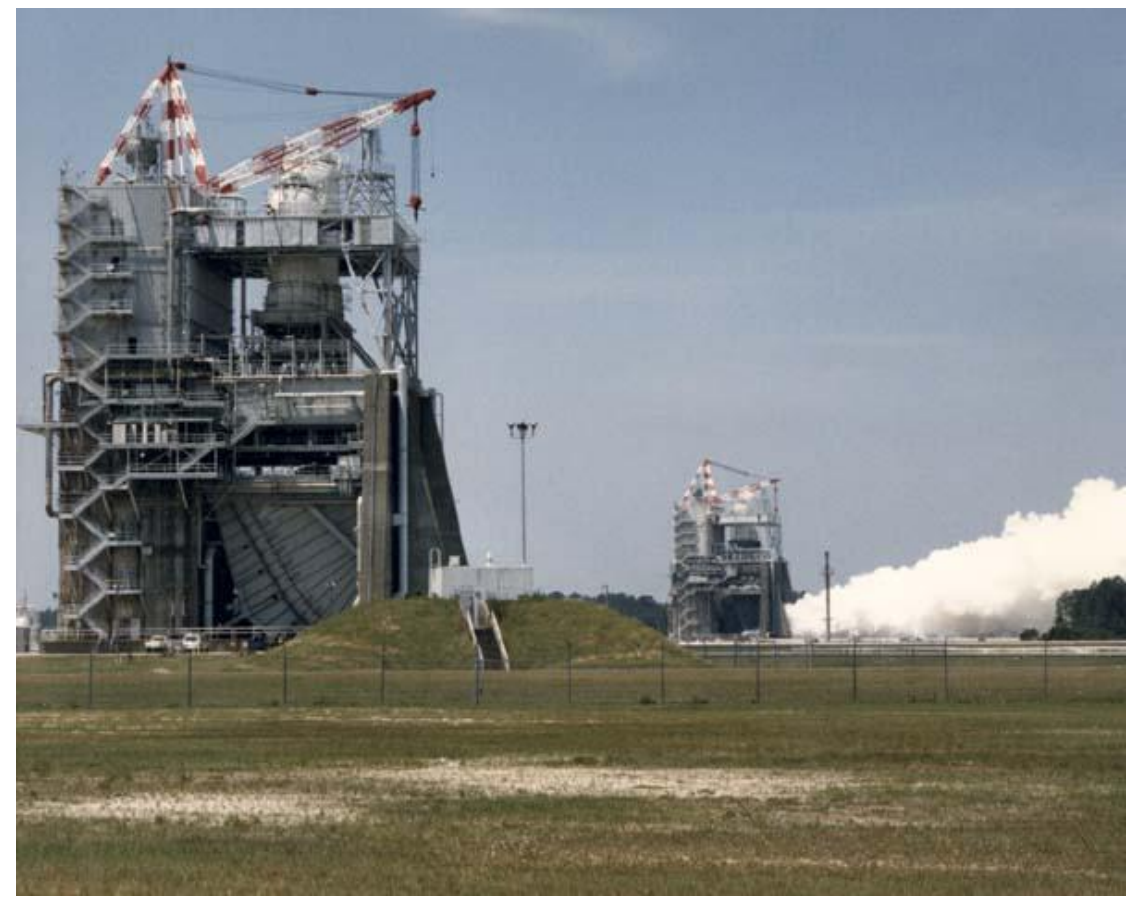

Figure 10. Stennis test stands A2, foreground, and A1, background during SSME test

In addition to modifying test stands, Stennis is also building and activating the new A3 test stand. This unique new national capability will support high-altitude, full-duration, full-gimbal development, certification and flight engine acceptance testing of large liquid rocket engines such as the J-2X. It will support nozzle extension development and certification and engine performance verification. It can simulate altitudes of 80,000 to 100,000 
feet and support operating times of up to 500 seconds. Altitude simulation is accomplished via a steam ejector system in the diffuser, fed by chemical steam generators making the steam by burning isopropyl alcohol (IPA) and LOX and mixing it with water.

The foundation and structural steel for the A3 tower are complete, as well as stairs, platforms, handrails, and much of the lighting. The barge docks are complete. The shop building foundation is in place. The IPA unloading dock is complete. Lines and piping were being installed at the time this paper was drafted. Three LOX tanks, two IPA tanks, and six of nine planned water tanks, were installed beside the stand as of early 2010. The A3 isolation valve, test cell, diffuser and chemical steam generator (CSG) cans are in various stages of fabrication. Hydrogen transfer lines from the barge dock to the stand and the LOX and LH2 facility run tanks will be installed in 2010 . The stand will use nine "skids" of 3 chemical steam generator (CSG) cans each. The first skid was due to go to the E2 test complex for testing in 2010 before being moved to the stand. The thrust measurement system (TMS) is on the site awaiting installation. Installation of the gaseous nitrogen bottles to be used by the chemical steam generators also will began in 2010 . They also will provide pressurization gas needed to supply propellants to the generators. Subscale diffuser testing and CSG testing in the Stennis E test complexwere completed in 2009, demonstrating the method to be used to demonstrate A3's altitude simulation method. Construction and activation of A3 is scheduled to be completed in 2012. The team continues to mature the concept of operations plan, facility activation plan, and prepare the E2 facility to accept and test the first chemical steam generator skid in June 2010. Progress on the A3 stand is shown in Figure 11.
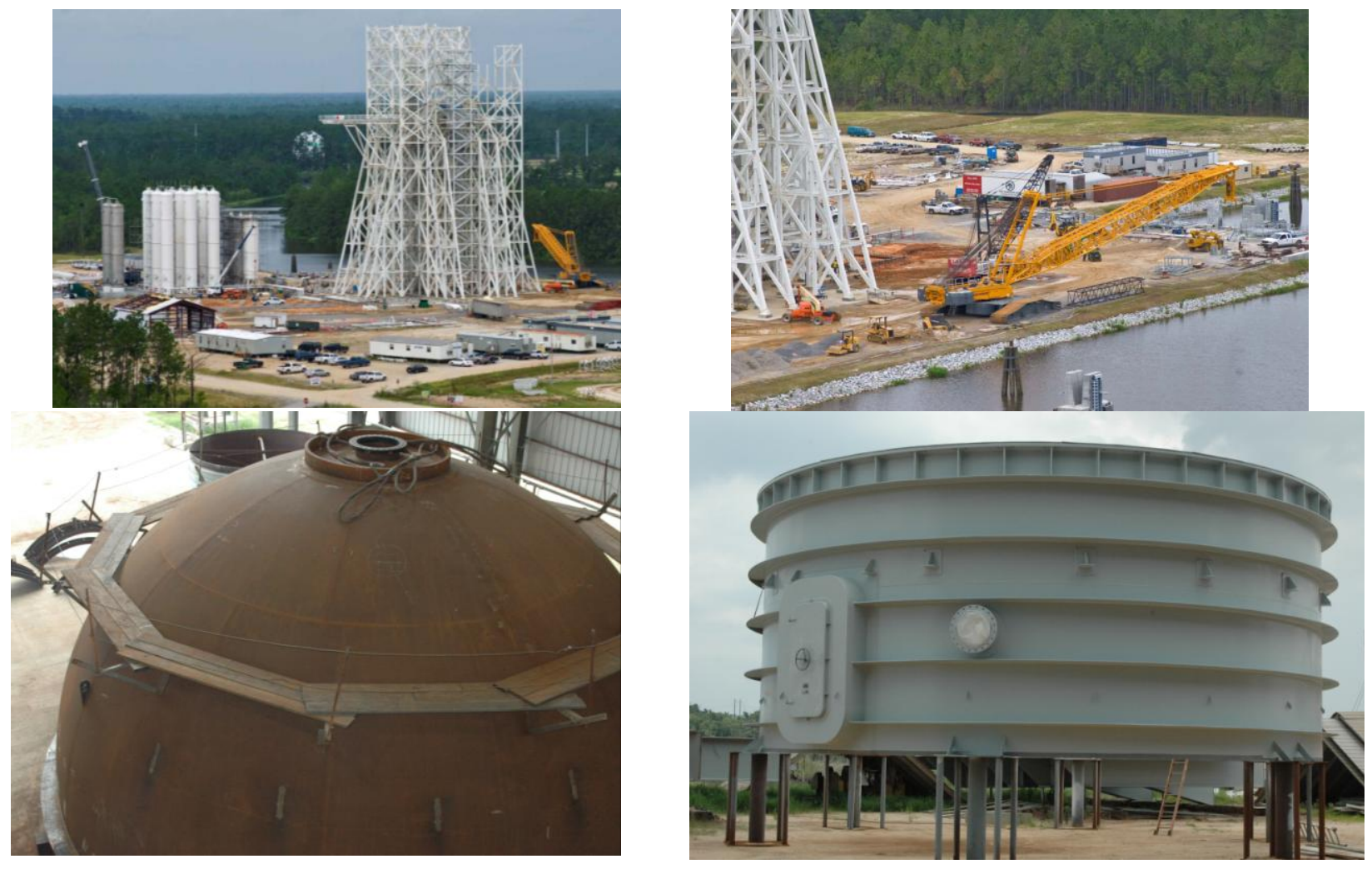

Figure 11. A3 test site, June 2010, clockwise from upper left: stand and IPA, water and LOX tanks; crane, test cell bottom section; and test cell dome 


\section{Conclusion}

Building on five decades of leadership in space propulsion in the United States, NASA is developing a new upper stage engine that marries simplicity to high performance. Development of the J-2X engine has made significant progress in the past year to reach an advanced stage of manufacturing. Today, thousands of large and small parts for of the first development engines are manufactured and ready for assembly in 2010, leading to system hot fire testing in early 2011. The J-2X represents a capability critical to any future direction in human exploration beyond Earth orbit. The government/industry team is currently focused on delivering the first completed development engine in late 2010 and the Power Pack 2 in early 2011, both scheduled for their first tests in early 2011. Several risks remain, including nozzle extension thermal performance, turbine blade life, gas generator stability, engine loads, and inlet duct life issues. These risks continue to be mitigated via analyses, component tests and planning ofr engine system tests. All these risk are currently mitigated sufficiently to proceed with Power Pack and engine system testing. The $\mathrm{J}-2 \mathrm{X}$ team is aggressively pursuing the start of sysem testing to make this engine available to decision makers for future space exploration needs. 


\section{Design Overview}

- Mission:

Common upper stage engine for Ares I and Ares V

- Key Features:

- LOX/LH ${ }_{2}$ GG cycle

- Series turbines with throttle capability through Lox turbine bypass

- Open loop, pneumatically actuated valves

- On-board engine controller and health monitoring

- Tube-wall regen nozzle/large passively-cooled nozzle extension, turbine exhaust gas boost/cooling

- Helium spin start - with on-orbit restart capability

\section{- Development Philosophy:}

Evolved hardware and mature technology where possible, aggressive schedule, early risk reduction testing, requirements-driven
- USE Key Requirements

- Vacuum Thrust: 294,000 lbf (1307 kN)

- Specific impulse: $448 \mathrm{sec}$ (min)

- Mixture ratio: 5.5

- Run duration: 500 seconds

- Weight: 5,535 (2,516 kg)

- Size: 120" dia x 185" long

- Life: 8 starts / $2600 \mathrm{sec}$

- Ares V specific: on-orbit restart, $82 \%$ thrust (4.5 mixture ratio)

- Major Hardware Flow

- Production - Pratt \& Whitney Rocketdyne, Canoga Park, CA

- Engine assembly - SSC, MS, Bldg 9101

- Test - SSC, MS, Stands A1, A2, A3

- Stage integration - MAF, LA 


\section{Engine Hardware - Established at CDR 2008}

10 DDT\&E Engines

- Development ground test engines (5)

- Certification ground test engines - (2)

- Upper Stage ISTA ground test engine - (1)

- Orion 1 flight test engine - (1)

- Full unassembled engine - (1)

- 2 Powerpack Assemblies

- Heritage J-2/J-2S Powerpack - (1)

- J-2X Powerpack - (1)

- 4 Long Lead Hardware Sets

- Represents first 18 months of engine manufacturing

- 1 Engine Mass Simulator

- IVGVT

- 9 Nozzle Extensions

- Full Length - (7)

- Stub Length for SSC A2/A3 - (2)



1 Set Spare Fuel and Oxidizer Turbopumps

1 Set Hardware/software for J-2X Hardware in the Loop Laboratory

- 1 Control System for Ares SIL

- Engine Support Equipment

- Manufacturing Technology Demonstrators

Component Test Articles

Total 223 engine tests as follows:

-132 development tests

-32 certification tests

- 7 tests/flight - first Ares I test flight

- 15 tests as a part of Upper Stage

Integrated Stage Test Article

-17 contingency tests

-20 rework tests 


\section{Subscale Main Injector Testing, MSFC}

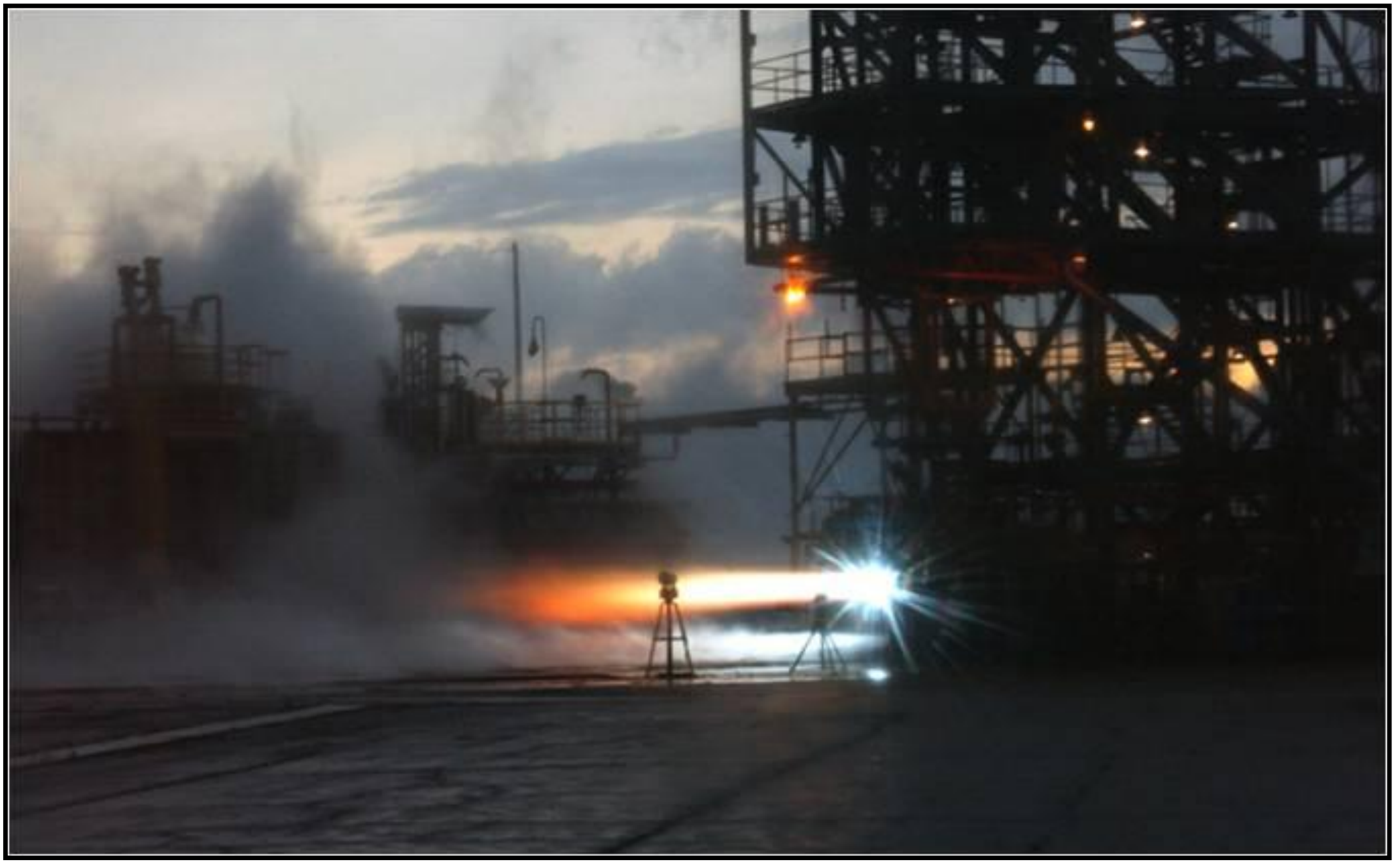




\section{Workhorse Gas Generator Testing at MSFC}





Stennis Space Center

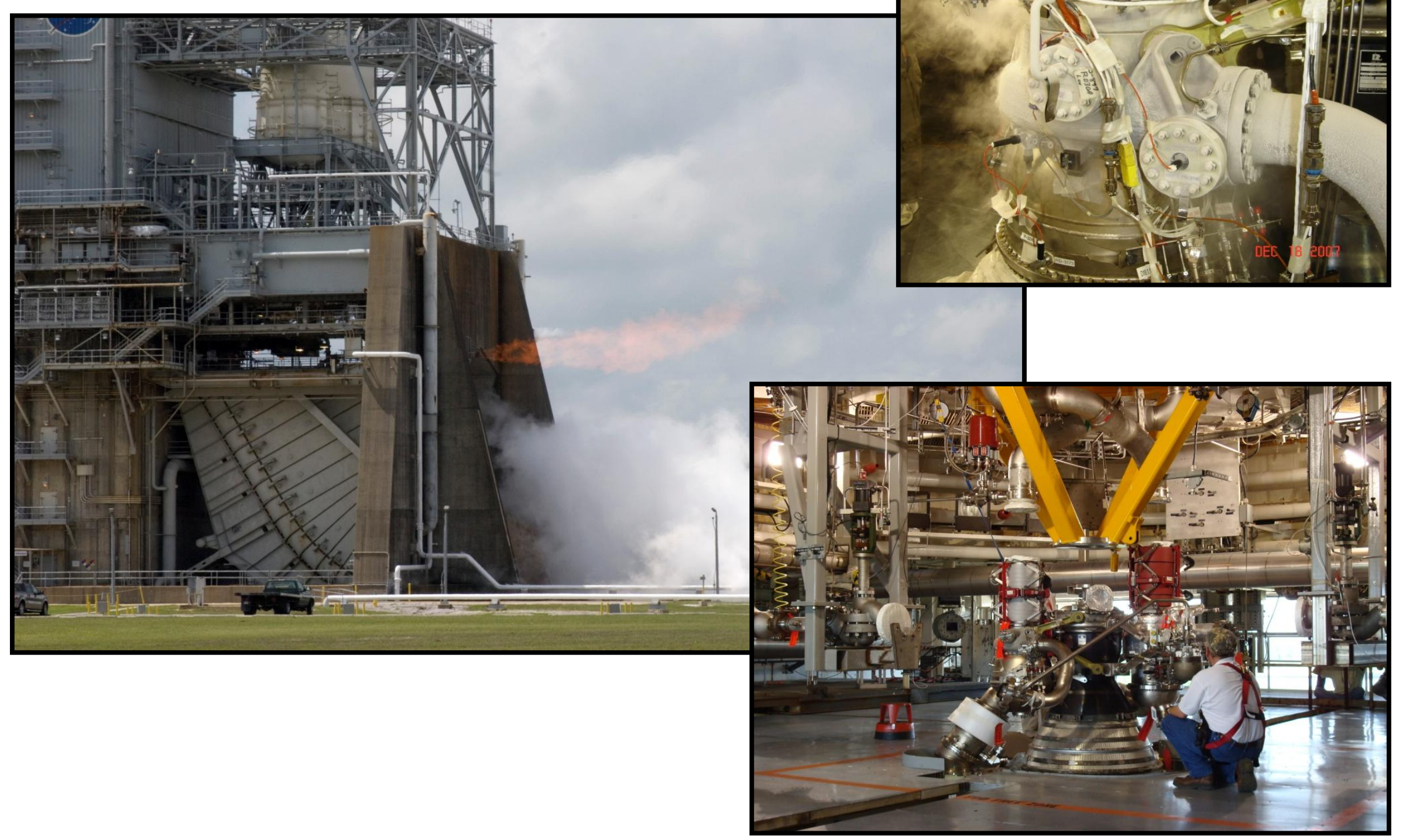






\section{Turbomachinery Testing}
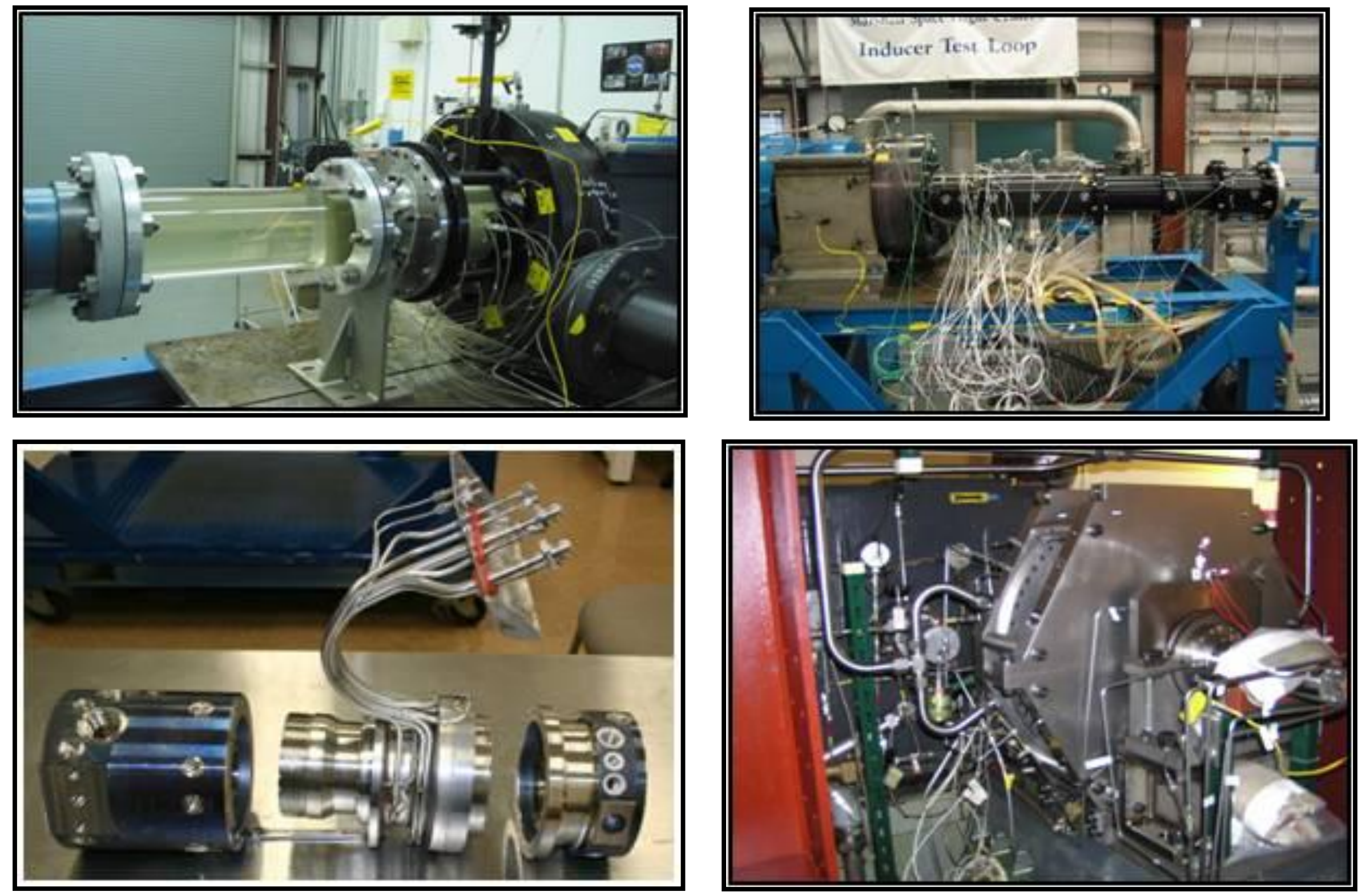


\section{Nozzle Extension Testing at MSFC}
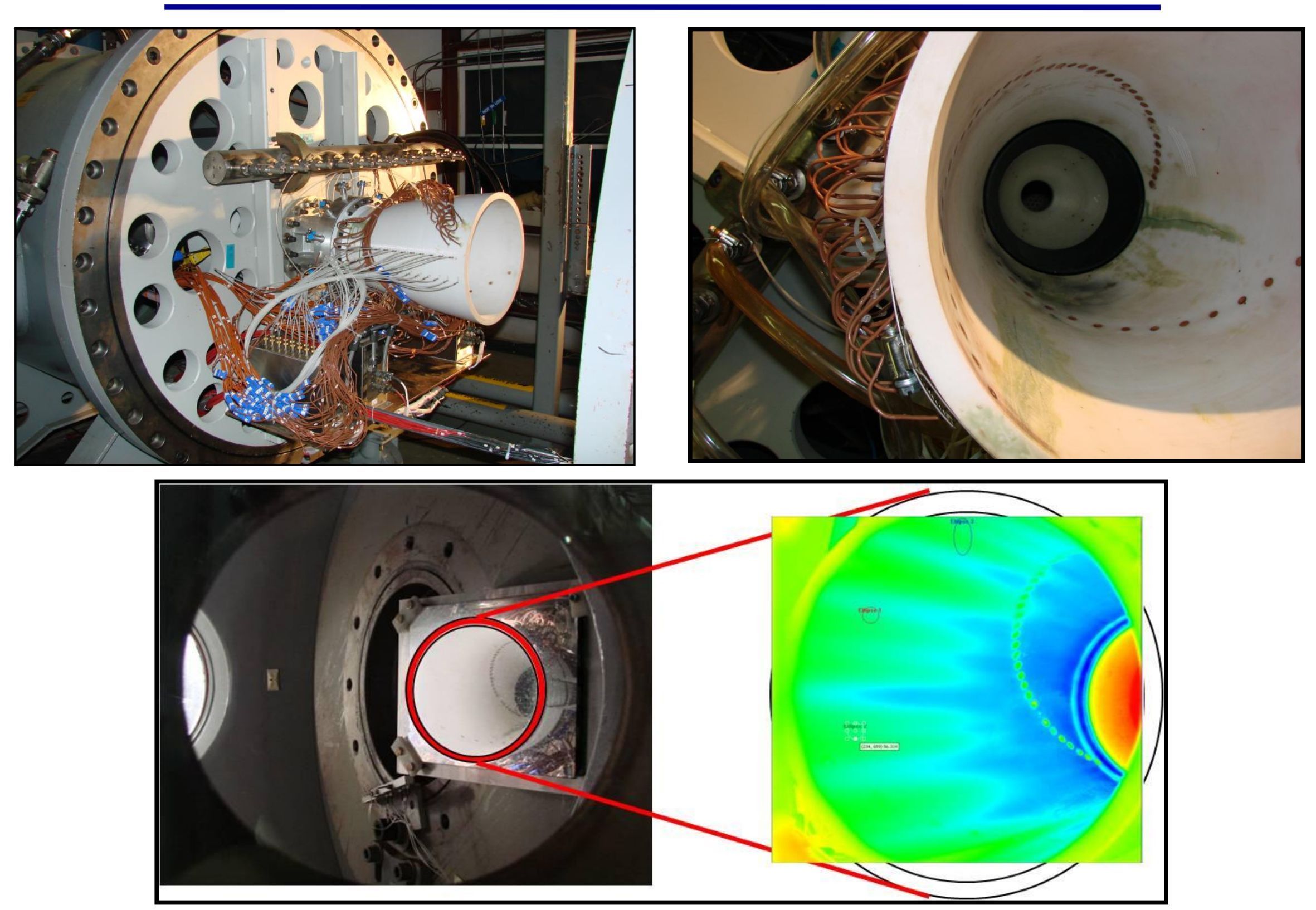


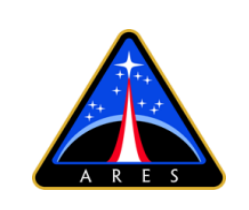

Nozzle Extension Thermal Emissivity Coating Tests at MSFC






\section{Hardware Manufacturing Highlights}
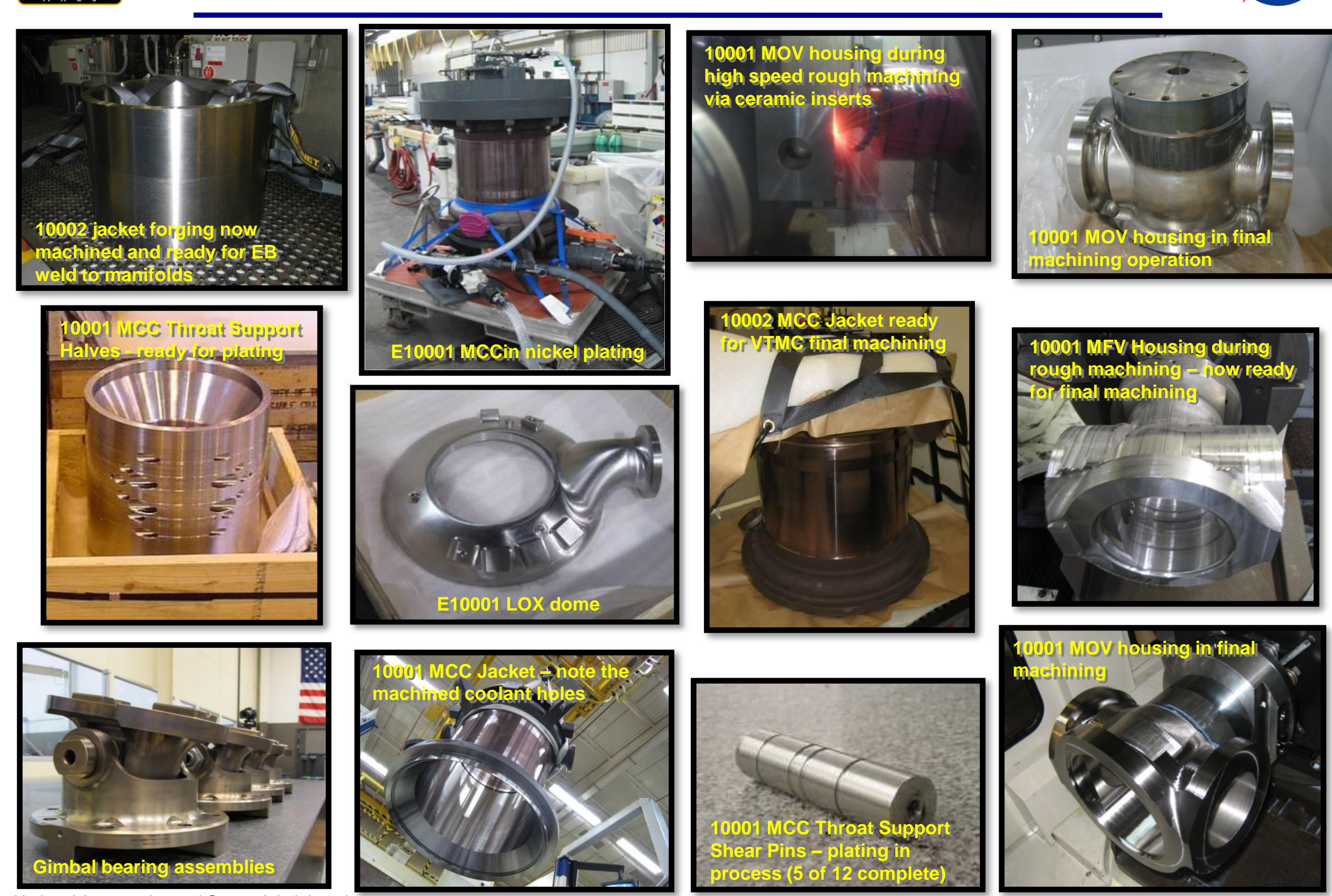


\section{Manufacturing Highlights, continued}
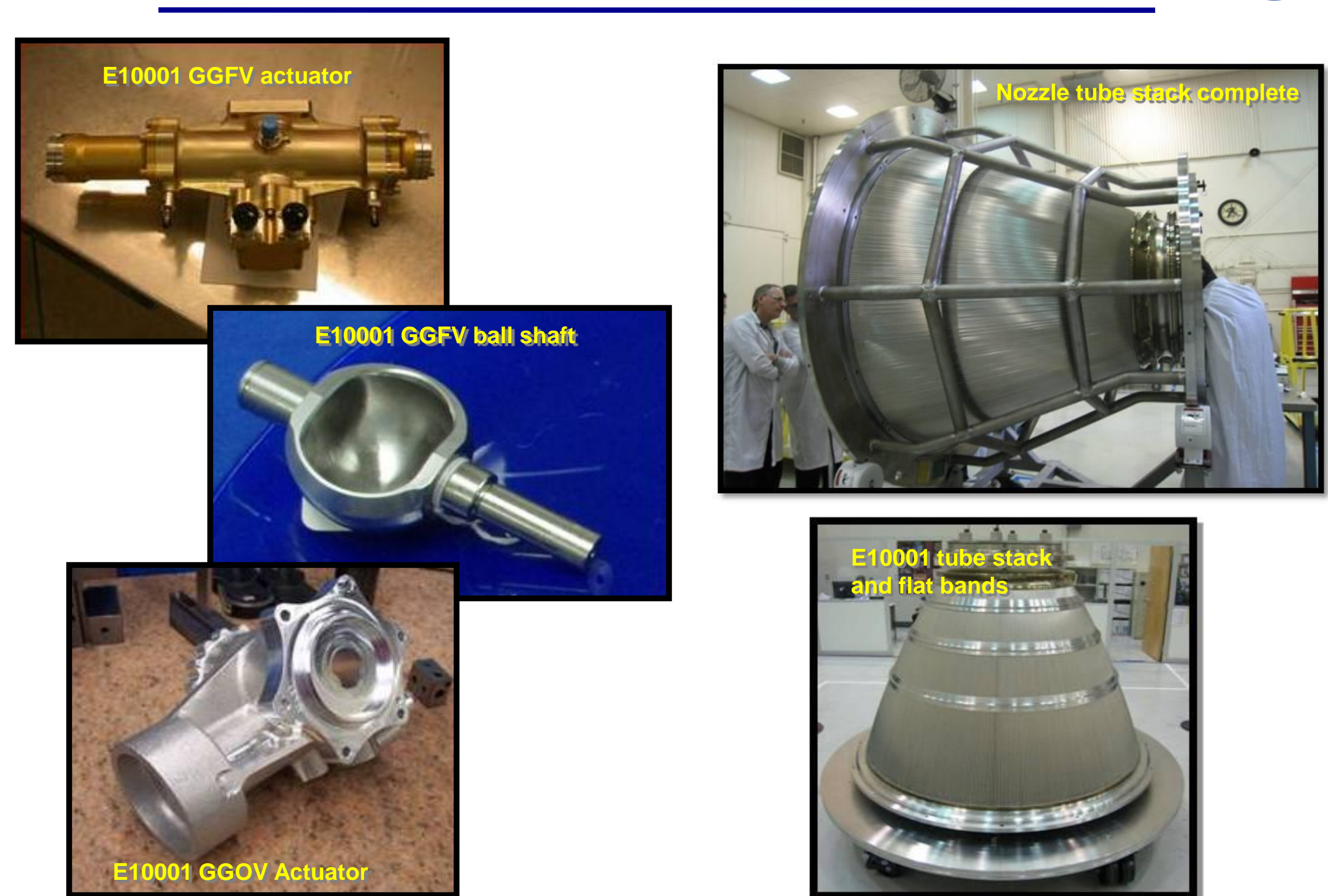


\section{Manufacturing Highlights: Turbomachinery}

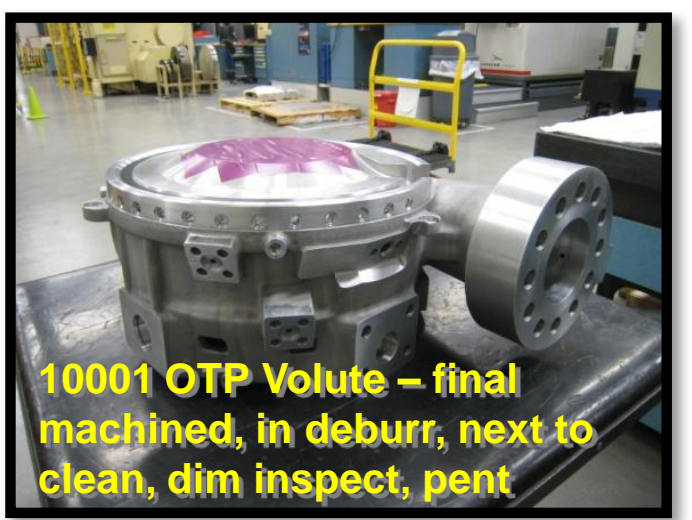

10001 FTP Turbine Mantioldsclean and heat treat 23535
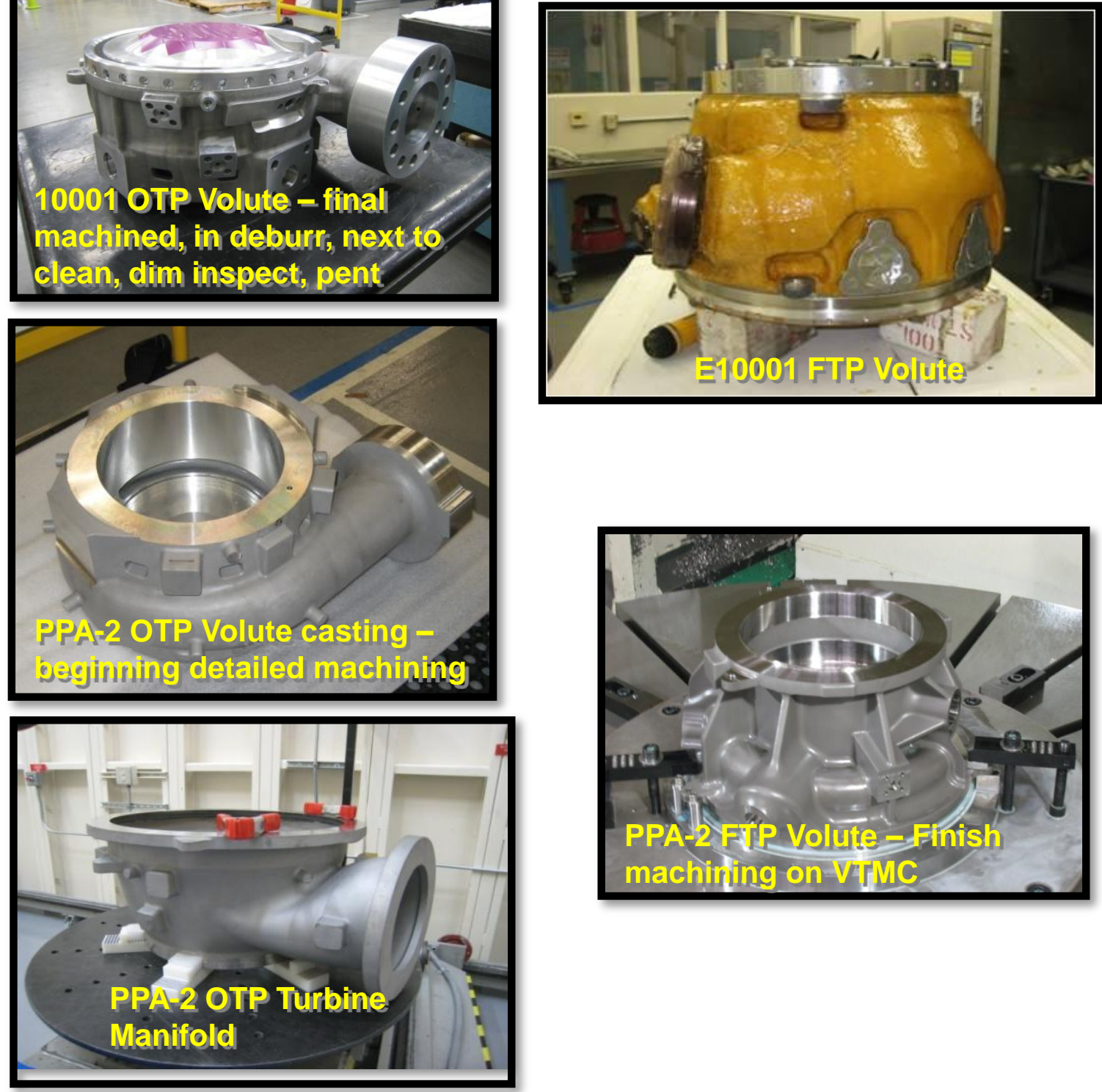

10001 OTP Turbine Manifold ready for torus welding






\section{Manufacturing Progress: Nozzle Extension}


Chem Mifill Facility

Preparation
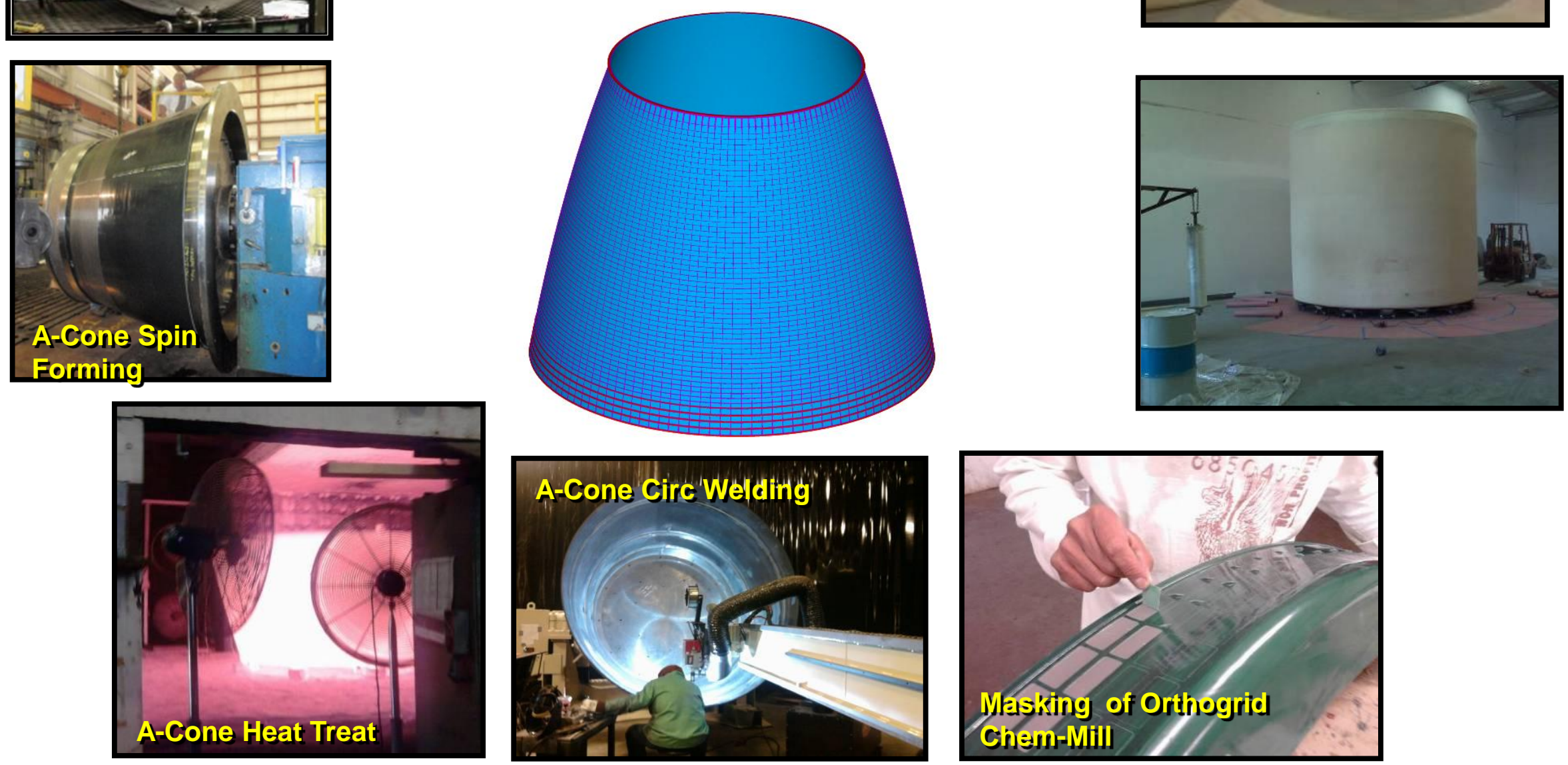


\section{Test Facilities: A1 \& A2 Test Stands}

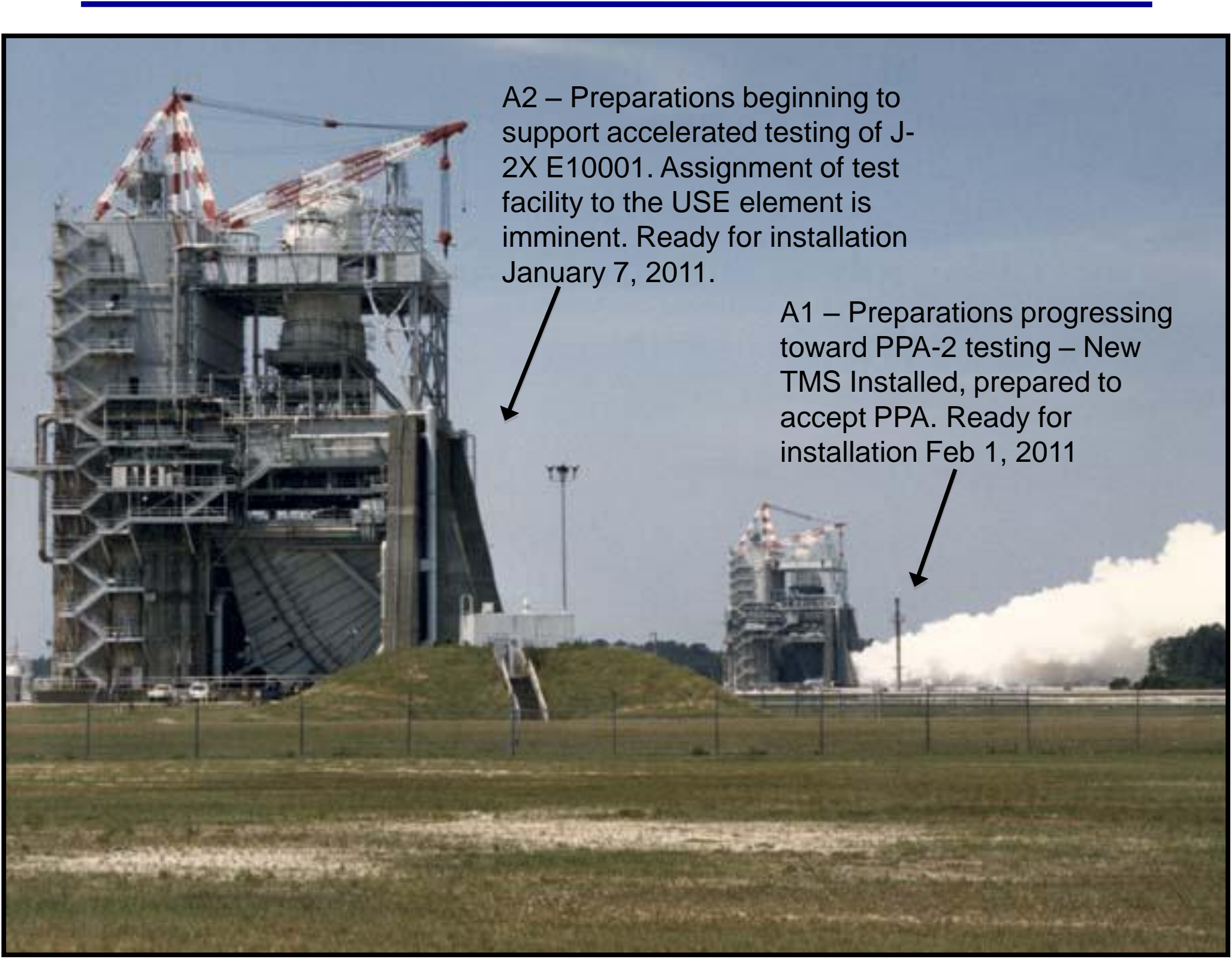




\section{Test Facilities: A3 Construction}





